\title{
EVALUASI KONDISI JARINGAN DAN PERKERASAN JALAN DI LINGKUNGAN KELURAHAN GILINGAN SURAKARTA
}

\author{
Teguh Yuono, S.T.,M.T \\ Program Studi Teknik Sipil, Fakultas Teknik, Universitas Tunas Pembangunan Surakarta \\ yuonoteguh.ty@utp.ac.id \\ Kukuh Kurniawan Dwi Sungkono, S.T.,M.Eng \\ Program Studi Teknik Sipil, Fakultas Teknik, Universitas Tunas Pembangunan Surakarta \\ kukuhkds.utpska@gmail.com
}

\begin{abstract}
Abstrak
Jaringan jalan mempunyai fungsi yang sangat penting yaitu sebagai prasarana untuk memindahkan orang maupun barang, mendorong pertumbuhan ekonomi dan upaya pemerataan pembangunan. Besarnya frekuensi kendaraan yang melewati sebuah jalan menyebabkan jalan menjadi mudah aus dan rusak. Perbaikan atau pemeliharaan rutin diperlukan agar kerusakan yang lebih parah dapat dihindari. Perencanaan yang matang sangat dibutuhkan masyarakat agar jalan selalu dalam kondisi baik sehingga dapat memberikan pelayanan yang optimal. Diperlukan identifikasi kondisi jaringan dan perkerasan jalan pada tiap wilayah sehingga tepat upaya penanganannya. Tahapan penelitian ini meliputi: pemetaan jaringan jalan, identifikasi jenis perkerasan, inventarisasi kerusakan perkerasan jalan dan penyusunan rencana perbaikan kerusakan. Hasil penelitian didapatkan jaringan jalan yang ada telah terkoneksi dari jalan kecil (gang) ke jalan lingkungan sampai ke jalan besar. Ada empat jenis perkerasan jalan dilokasi penelitian yaitu jalan aspal, jalan beton, jalan paving dan jalan tanah, dengan didominasi jalan aspal sepanjang 18,875 km. Umumnya kondisi jalan masih baik tetapi dijumpai kerusakan pada beberapa jalan. Pada jalan aspal dijumpai kerusakan : penurunan, pelat terbagi, retak, kerusakan penutup sambungan, dan kerusakan permukaan. Pada jalan beton ditemukan kerusakan deformasi, retak, disintegrasi, pinggir turun, tambalan, lubang dan kerusakan penutup sambungan. Perlu dilakukan perbaikan kerusakan sesegera mungkin agar kerusakan tidak meluas.
\end{abstract}

Kata kunci: jaringan jalan, kondisi, perbaikan kerusakan.

\begin{abstract}
The road network has a very important function, namely as an infrastructure for moving people and goods, encouraging economic growth and equitable development efforts. The frequency of vehicles passing through a road causes the road to become easily worn and damaged. Regular repairs or maintenance are needed so that more severe damage can be avoided. Careful planning is needed by the community so that the road is always in good condition so that it can provide optimal service. Identification of network conditions and road pavement is needed in each region so that appropriate efforts to handle it. The stages of this study include: road network mapping, identification of types of pavement, inventory of road pavement damage and preparation of damage repair plans. The results showed that the existing road network was connected from a small road (alley) to the road to the road to the main road. There are four types of pavement in the research location, namely asphalt road, concrete road, paving road and dirt road, dominated by $18,875 \mathrm{~km}$ of asphalt road. Generally the road conditions are still good but damage to some roads is found. Damage found on the asphalt road: drop, divided plate, cracks, damage to the connection cover, and surface damage. On the concrete road, deformation, cracks, disintegration, down
\end{abstract}


edges, patches, holes and damage to the joints were found to be damaged. Damage repair needs to be done as soon as possible so that damage does not spread.

Keywords: road network, conditions, repair damage.

\section{PENDAHULUAN}

Jaringan jalan mempunyai fungsi yang sangat penting yaitu sebagai prasarana untuk memindahkan orang maupun barang, mendorong pertumbuhan ekonomi dan upaya pemerataan pembangunan.

Dalam dimensi yang lebih luas, jaringan jalan mempunyai peranan yang penting dalam pengembangan suatu wilayah baik kota atau kabupaten, propinsi bahkan nasional.

Bertambahnya jumlah penduduk pada suatu wilayah menjadikan bertambahnya hunian sehingga menyebabkan kepadatan dan meningkatkan mobilitas warga masyarakatnya.

Besarnya frekuensi kendaraan yang melewati sebuah jalan menyebabkan jalan menjadi mudah aus dan rusak. Perbaikan atau pemeliharaan rutin diperlukan agar kerusakan yang lebih parah dapat dihindari. Perencanaan yang matang sangat dibutuhkan masyarakat agar jalan selalu dalam kondisi baik sehingga dapat memberikan pelayanan yang optimal. Wilayah RT,RW dan kelurahan banyak yang belum memiliki dokumen kondisi jalan dan upaya penanganan.

Kelurahan Gilingan merupakan sebuah kawasan padat penduduk di Kecamatan Banjarsari yang stategis karena di wilayahnya terdapat terminal utama Kota Surakarta. Hal ini menarik untuk dilakukan kajian terkait persoalan kondisi jalan yang ada di wilayah tersebut.

Dari latar belakang tersebut dapat dirumuskan masalahnya, sebagai berikut : 1). bagaimana jaringan jalan di wilayah Gilingan, 2). bagaimana jenis-jenis perkerasan jalan di wilayah Gilingan, 3). bagaimana jenis-jenis kerusakan jalan yang ada di wilayah Gilingan, 4). bagaimana solusi penanganan kerusakan jalan yang ada di wilayah Gilingan.

Tujuan dari penelitian ini adalah 1). mengetahui jaringan jalan di wilayah Gilingan, 2). mengetahui jenis-jenis perkerasan yang ada di wilayah Gilingan, 3). mengidentifikasi kerusakan jalan yang terjadi di wilayah Gilingan, 4). menyusun dokumen perencanaan untuk perbaikan jalan di wilayah Gilingan.Secara umum, manuskrip disusun dalam subjudul yang terdiri atas

\section{LANDASAN TEORI Jaringan Jalan}

Jaringan jalan adalah satu kesatuan jaringan jalan yang terdiri atas sistem jaringan primer dan sistem jaringan jalan sekunder yang terjalin dalam hubungan hierarkis. Sedangkan sistem jaringan jalan adalah satu kesatuan ruas jalan yang saling menghubungkan dan mengikat pusat-pusat pertumbuhan dengan wilayah yang berada dalam pengaruh pelayanannya dalam satu hubungan hierarkis atau pengelompokan jalan(https://id.wikipedia.org/wiki/jaring an_jal-an).

\section{Perkerasan Jalan}

Perkerasan jalan adalah lapisan kulit atau permukaan keras yang diletakkan pada formasi tanah setelah selesainya pekerjaan tanah. Perkerasan jalan dapat diklasifikasikan menjadi tiga, yaitu: perkerasan kaku, perkerasan lentur dan perkerasan komposit (Ari Suryawan, 2009).

Perkerasan kaku adalah perkerasan beton semen yang dibuat dari campuran semen, pasir dan batu pecah dengan atau tanpa tulangan (Pedoman pelaksanaan perkerasan jalan beton semen, Depkimpraswil 2004). 
Konstruksi perkerasan lentur adalah perkerasan yang mengunakan aspal sebagai pengikat. Lapisan-lapisan perkerasannya bersifat memikul beban.(Silvia Sukirman, 1999).

Perkerasan komposit adalah perkerasan kaku yang dikombinasikan dengan perkerasan lentur, dapat berupa perkerasan lentur diatas perkerasan kaku atau perkerasan kaku diatas perkerasan lentur (Silvia Sukirman, 1999).

Paving block adalah suatu komposisi bahan bangunan yang dibuat dari campuran semen portland atau bahan perekat hidrolis sejenisnva, air dan agregat dengan atau tanpa bahan tambahan lainnya yang tidak mengurangi mutu bata beton (bata beton paving block, SNI 03-06911996). Jalan paving mudah bergelombang bila pondasinya tidak kuat dan kurang nyaman untuk kendaraan dengan kecepatan tinggi. Sehingga perkerasan paving block hanya cocok untuk mengendalikan kecepatan kendaraan di lingkungan permukiman dan perkotaan yang padat

\section{Jenis Kerusakan Perkerasan}

Menurut Hary Christady Hardiyatmo, 2007, jenis kerusakan pada perkerasan jalan dikelompokkan menjadi dua macam, yaitu :

1. Kerusakan struktural adalah kerusakan pada struktur jalan, sebagian atau keseluruhannya yang menyebabkan perkerasan jalan tidak lagi mampu mendukung beban lalu lintas.

2. Kerusakan fungsional adalah kerusakan pada permukaan jalan yang dapat menyebabkan terganggunya fungsi jalan..

Kerusakan perkerasan beton sering terjadi akibat turunnya kualitas bahan. Perkembangan retak sering terjadi yang pada akhirnya merusak seluruh area perkerasan. Kerusakan perkerasan kaku dapat diklasifikasikan sebagi berikut :
1. Deformasi (deformation).

2. Retak (cracks).

3. Disintegrasi (disintegration).

4. Pinggir turun (lane/shoulder dropoff).

5. Tambalan dan galian utilitas (patching and utility cuts).

6. Lubang (pothole).

7. Kerusakan penutup sambungan (joint seal damage).

Jenis-jenis kerusakan perkerasan lentur (Hary Christady Hardiyatmo, 2007), sebagai berikut :

1. Deformasi : bergelombang, alur, ambles, sungkur, mengembang, benjol dan turun.

2. Retak : memanjang, melintang, diagonal, reflektif, blok, kulit buaya dan bulan sabit.

3. Kerusakan tektur permukaan : butiran lepas, kegemukan, agregat licin, terkelupas dan stripping.

4. Kerusakan lubang, tambalan dan persilangan jalan rel.

5. Kerusakan dipinggir perkerasan : pingging pecah/retak dan bahu turun.

Jenis-jenis kerusakan perkerasan paving block, sebagai berikut :

1. Paving retak atau pecah, hal ini dikarenanakan kualitas bahan penyusun yang kurang baik dan adanya beban yang berat.

2. Permukaan perkerasan paving tidak rata akibat adanya penurunan pada pondasi bawahnya.

3. Permukaan licin karena berlumut.

4. Tumbuhnya rumput pada sela-sela sambungan paving.

\section{Perbaikan Kerusakan Perkerasan}

Perbaikan perkerasan kaku untuk kerusakan retak dimana celah yang kecil kurang dari $5 \mathrm{~mm}$ maka dilakukan pengisian celah dengan aspal, sedang jika celah retak lebar lebih dari $5 \mathrm{~mm}$ maka dilakukan pembangunan kembali pelat secara lokal (Shahin,1994).

Perbaikan perkerasan lentur untuk tipe kerusakan deformasi berupa ambles, perbaikan dilakukan dengan menambal 
(Shahin,1994).

Cara memperbaiki perkerasan paving block yang mengalami kerusakan retak atau pecah adalah dengan melakukan penggantian paving yang rusak dengan paving yang baru. Untuk memperbaiki permukaan perkerasan paving yang tidak rata, dilakukan dengan mengurangi atau menambahkan ketebalan alas pasir atau meratakan lapisan pondasi. Untuk mengatasi tumbuhnya rumput disela paving cukup dengan melakukan pembersihan saja.

\section{METODE PENELITIAN}

A. Lokasi Penelitian

Lokasi yang dijadikan sebagai objek penelitian ini jalan pada tiap RW di Kelurahan Gilingan Kecamatan Banjarsari Kota Surakarta.

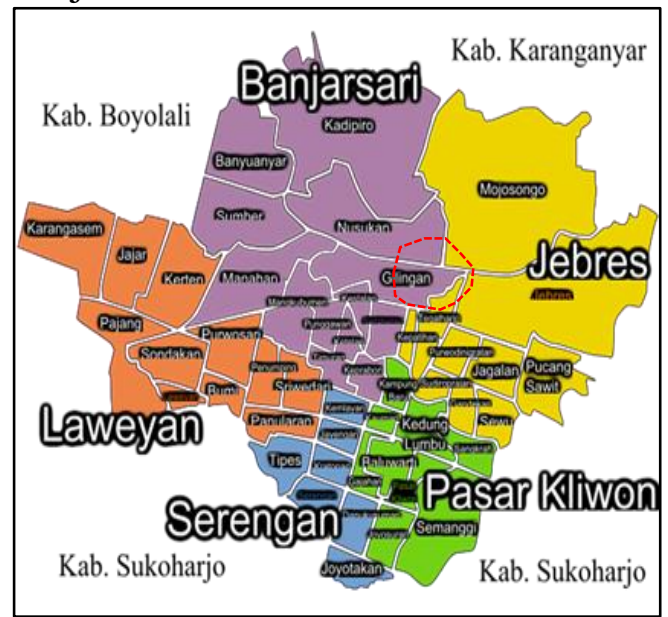

\section{Gambar (a). Peta Kota Surakarta}

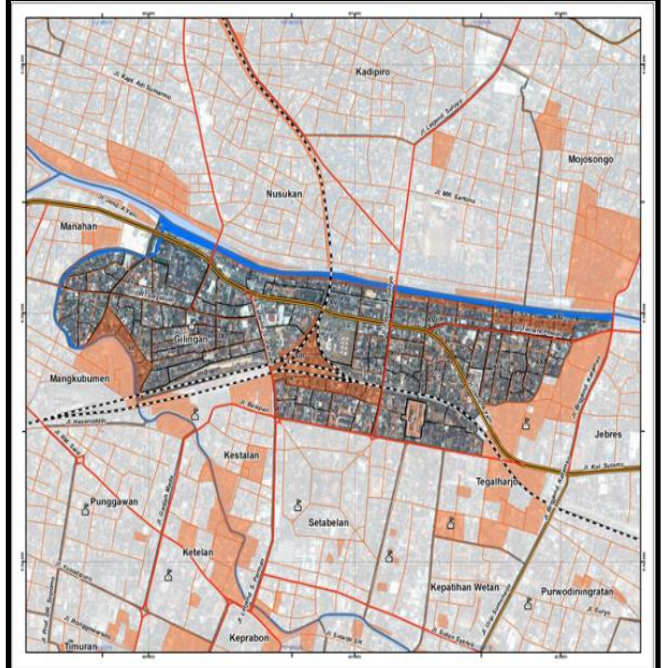

B. Gambar (b). Peta Kelurahan Gilingan Lokasi penelitian

\section{Pengumpulan Data}

Pengumpulan data dalam penelitian ini meliputi data primer maupun data sekunder yang nantinya digunakan sebagai bahan penelitian.

Data primer, didapatkan dengan melakukan survei lapangan, meliputi :

- data dimensi jalan;

- data jenis perkerasan jalan;

- data jenis-jenis kerusakan jalan;

Sedangkan data sekunder didapatkan dari pihak-pihak terkait (masyarakat, ketua RT, ketua RW dan pemerintah kelurahan), meliputi :

- data struktur perkerasan;

- data desain campuran; dan

- data waktu pelaksanaan.

\section{Peralatan}

Peralatan yang diperlukan adalah:

1. Alat ukur panjang, lebar dan dalam kerusakan perkerasan jalan menggunakan meteran rol $50 \mathrm{~m}$, meteran $5 \mathrm{~m}$ dan pengaris.

2. Alat untuk penanda segmen jalan menggunakan cat pilok.

3. Alat dokumentasi kerusakan perkerasan jalan menggunakan kamera digital.

Adapun perlengkapan penunjang lainnya, antara lain : alat tulis dan kalkulator.

\section{E. Teknis Analis Data}

Agar mempermudah dalam proses penelitian, maka penelitian ini dibagi dalam beberapa tahapan:

1. Tahapan persiapan

Meliputi kegiatan identifikasi dan perumusan masalah, studi literatur dan pengkajian teori serta persiapan peralatan-peralatan yang dibutuhkan di lapangan.

2. Tahapan pengumpulan data Kegiatan pengambilan data primer dan data sekunder.

3. Tahapan penelitian dan analisis 
Kerangka pikir tahapan penelitian dapat dilihat pada gambar di bawah ini.

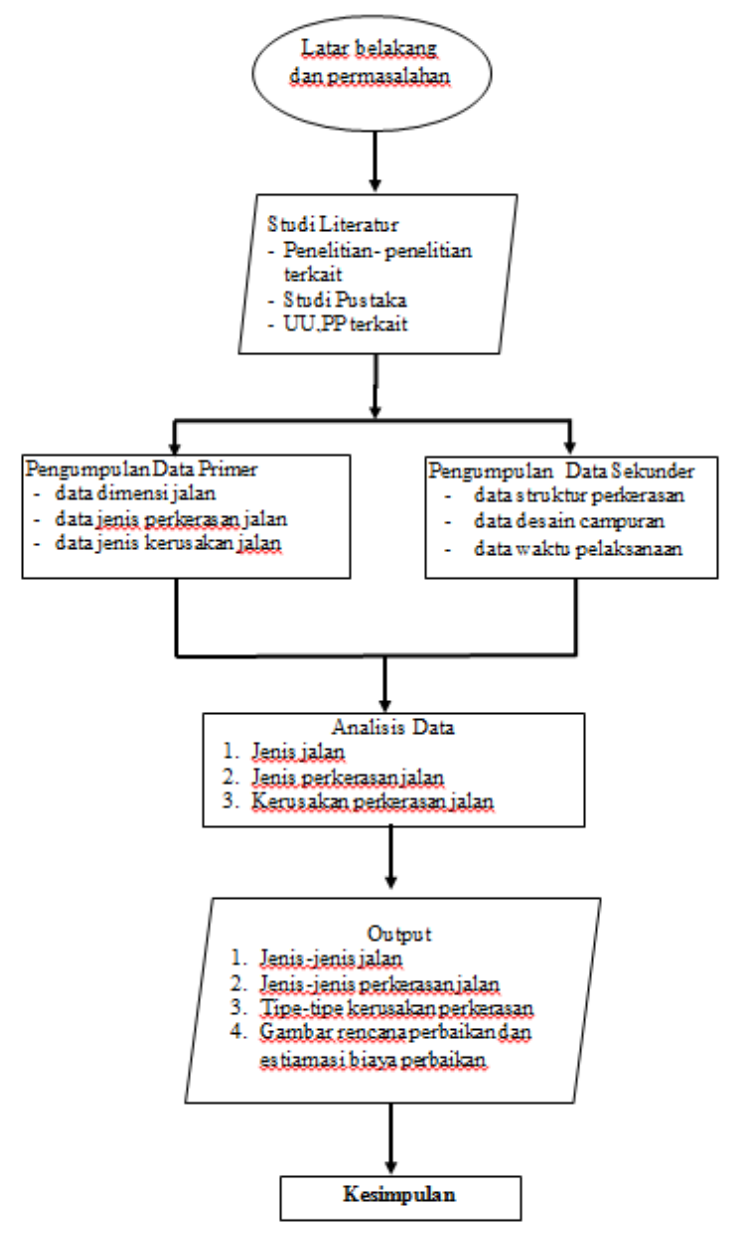

Gambar (c). Kerangka pikir penelitian

\section{HASIL DAN PEMBAHASAN}

\section{Analisis Data}

Analisis data jenis-jenis jalan, jenis perkerasan jalan, tipe-tipe kerusakan perkerasan jalan meliputi:

a. Pengumpulan data primer dengan penelusuran, pengamatan, pencatatan dan dokumentasi untuk mengetahui jenis-jenis jalan.

b. Pengumpulan data primer dengan penelusuran, pengamatan, pengukuran dimensi jalan, pencatatan dan dokumentasi untuk mengetahui jenis dan demensi perkerasan jalan.

c. Pengumpulan data primer dengan penelusuran, pengamatan kondisi perkerasan, pengukuran kerusakan jalan, ,pencatatan dan

dokumentasi untuk mengetahui tipe-tipe kerusakan dan tingkat kerusakan.
Analisis Jenis dan Perkerasan Jalan
Dari hasil pemetaan dilapangan untuk pada jaringan jalan di Kelurahan Gilingan dapat dijelaskan pada tabel 1 dan tebel 2 sebagai berikut : 
Tabel (a). Jenis Jalan

\begin{tabular}{|c|l|r|}
\hline No & \multicolumn{1}{|c|}{ Jenis Jalan } & \multicolumn{1}{c|}{ Panjang (m) } \\
\hline 1 & Jalan Gang & 4,444 \\
\hline 2 & Jalan Lingkungan & 12,983 \\
\hline 3 & Jalan Kota & 3,146 \\
\hline 4 & Jalan Nasiona/Propinsi & 2,744 \\
\hline & Jumlah & $\mathbf{2 3 , 3 1 6}$ \\
\hline
\end{tabular}

Tabel (b). Jenis Perkerasan Jalan

\begin{tabular}{|c|c|c|}
\hline No & Jenis Perkerasan Jalan & Panjang (m) \\
\hline 1 & Jalan Aspal & 18,875 \\
\hline 2 & Jalan Beton & 3,541 \\
\hline 3 & Jalan Paving & 503 \\
\hline 4 & Jalan Tanah & 398 \\
\hline & Jumlah & 23,316 \\
\hline
\end{tabular}

\section{Analisis Tipe-tipe Kerusakan Jalan}

Hasil penelitian di lokasi penelitian.

Ditemukan tipe-tipe kerusakan jalan

beton sebagai berikut :

1) Penurunan atau patahan.

2) Pelat terbagi (divided slab).

3) Retak : melintang, memanjang dan blok.

4) Kerusakan penutup sambungan.

5) Kerusakan permukaan : lepasnya agregat (scaling), agregat licin (polished aggregate).
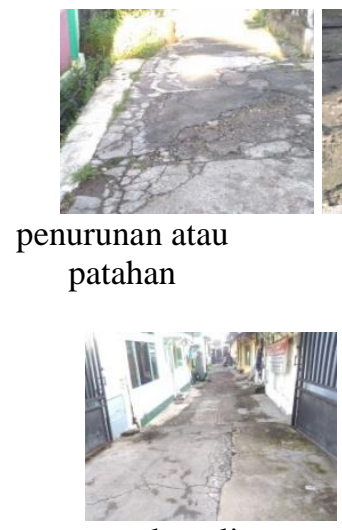

retak melintang

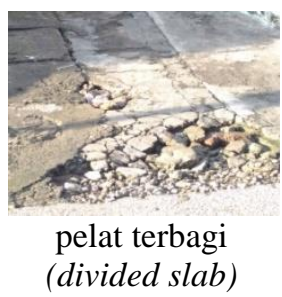

(divided slab)

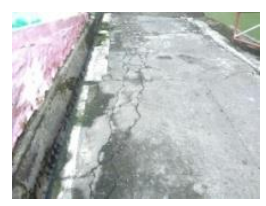

retak blok

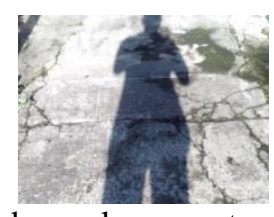

kerusakan penutup sambungan

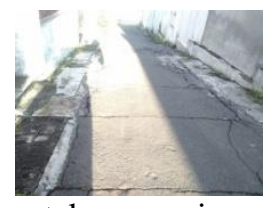

retak memanjang

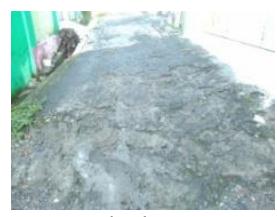

terkelupas

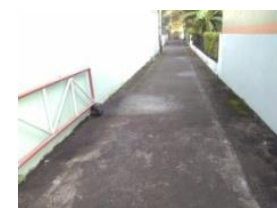

agregat licin

Gambar (d). Tipe kerusakan jalan beton yang terjadi

Di lokasi penelitian ditemukan tipe-tipe kerusakan jalan aspal sebagai berikut :

1. Deformasi : ambles, benjol dan turun.

2. Retak : memanjang, melintang, dan blok.
3. Kerusakan tektur permukaan : butiran lepas, agregat licin dan terkelupas.

4. Kerusakan lubang dan tambalan.

5. Kerusakan dipinggir perkerasan : pinggir pecah atau retak.

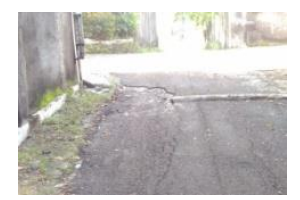

deformasi: ambles

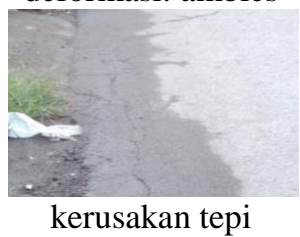

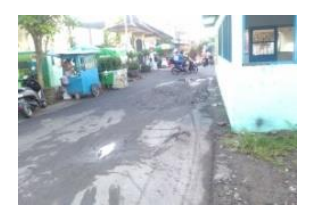

deformasi: turun

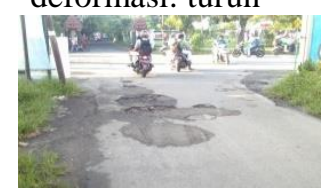

kerusakan tambalan

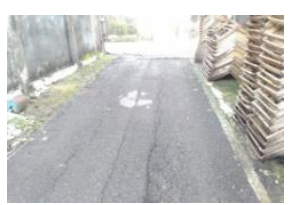

retak memanjang

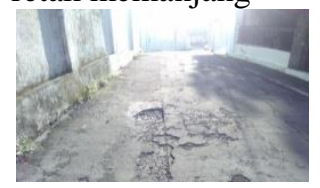

berlubang

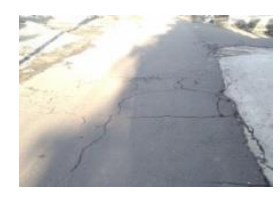

retak melintang

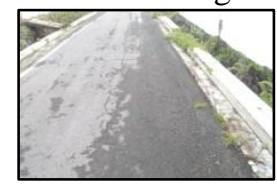

kerusakan tektur permukaan : butiran lepas

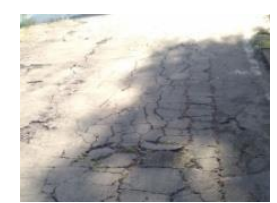

retak blok

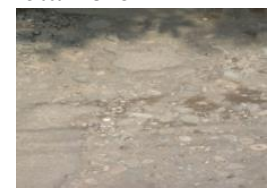

kerusakan tektur permukaan : agregat licin

Gambar (e). Tipe kerusakan jalan aspal yang terjadi

\section{Analisis Perbaikan Kerusakan Jalan}


Perbaikan kerusakan perkerasan kaku atau jalan beton dilakukan dengan membongkar pelat yang rusak kemudian dilakukan pengecoran kembali, lubang yang rusak dibersihkan kemudian ditambal setelah itu dipermukaan di gelar aspal hotmix 3 $\mathrm{cm}$.

Perbaikan kerusakan perkerasan lentur atau jalan aspal adalah dengan pembersihan kemudian dileveling penetrasi dilanjutkan dengan pelapisan aspal hotmix tebal $3 \mathrm{~cm}$.

Perbaikan kerusakan jalan paving adalah paving yang rusak diangkat, kemudian lapisan dibawahnya di ratakan kembali setelah itu dipasang paving yang baru.

Jalan yang masih tanah di perkuat pondasi jalannya dengan sirtu kemudian diatasnya di diperkeras dengan paving.

Tabel 3. Rencana Biaya Perbaikan Jalan
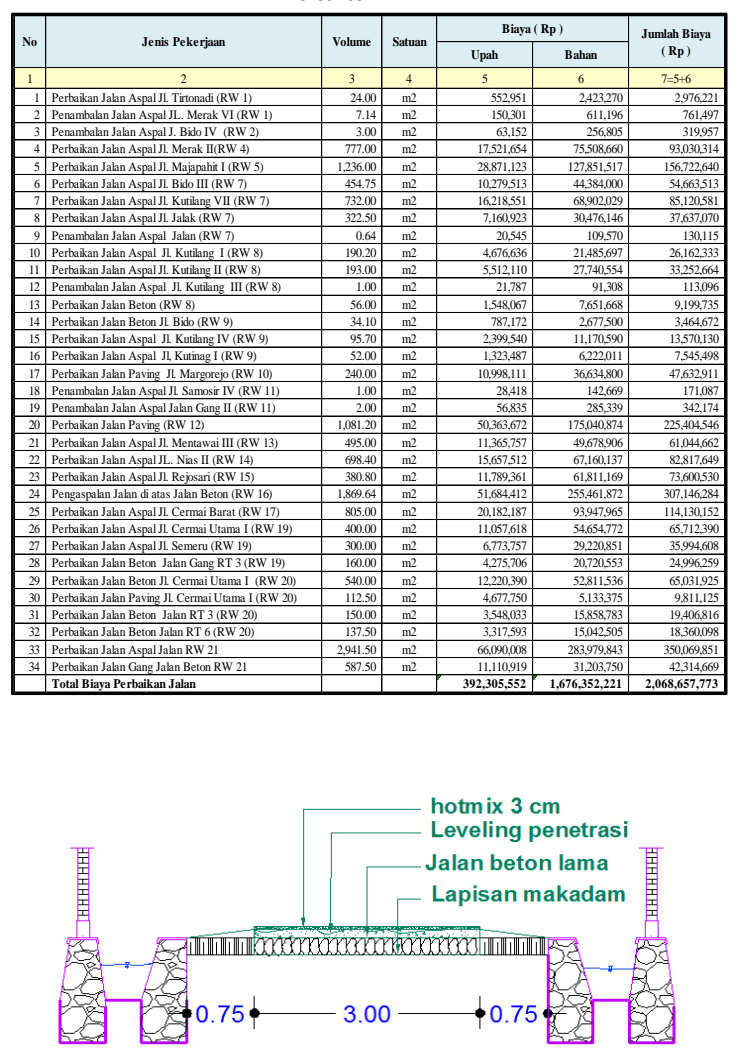

Gambar (f). Konstruksi perbaikan jalan

\section{KESIMPULAN DAN SARAN Kesimpulan}

Berdasarkan dari hasil analisa dan pembahasan dapat disimpulkan:

1. Jaringan jalan di wilayah Kelurahan Gilingan sudah menjangkau sampai kerumah-rumah warga. Jalan kecil (gang) terhubung ke jalan sedang (jalan lingkungan) kemudian terhubung ke jalan besar (jalan kota/propinsi/nasional).

2. Jenis konstruksi jalan di wilayah Kelurahan Gilingan yaitu jalan aspal, jalan beton dan jalan paving. Dimana jalan aspal mendominasi sepanjang $18.975 \mathrm{~m}$ dan masih ditemukan jalan tanah sepanjang $398 \mathrm{~m}$.

3. Terdapat kerusakan pada jalan beton, jalan aspal dan jalan paving dikarenakan usia jalan yang sudah tua, lalu lintas yang padat dan beban kendaraan yang melebihi batas tonase.

4. Hasil estimasi biaya perbaikan jalan berdasarkan kerusakan yang terjadi memerlukan anggaran 2,068 milyard rupiah.

\section{Saran}

Berdasarkan hasil analisa dan pembahasan, maka dapat disampaikan beberapa saran dan masukan demi perbaikan ke depan:
1. Kegiatan evaluasi atau pengecekan kondisi jalan perlu dilakukan secara periodik untuk mengetahui kondisi jalan yang ada sehingga perbaikan dapat dilakukan secepat mungkin agar kerusakan jalan tidak meluas.

2. Perbaikan kerusakan jalan sebaiknya di sesuaikan dengan tipe dan tingkat kerusakannya. 


\section{DAFTAR PUSTAKA}

Ari Suryawan. 2009. Perkerasan Jalan

Beton Semen Portland (Rigid

Pavement). Yogyakarta: Beta

Offset Yogyakarta.

Hary Christady Hardiyatmo. 2007. Pemeliharaan Jalan Raya,

Yogyakarta: Gadjah Mada

University Press.

Pd-T-05-2004-B. 2004. Pelaksanaan

Perkerasan Jalan Beton Semen.

Departeman Permukiman dan Prasarana Wilayah.

SNI 03-0691-1996. Bata beton (Paving block) 